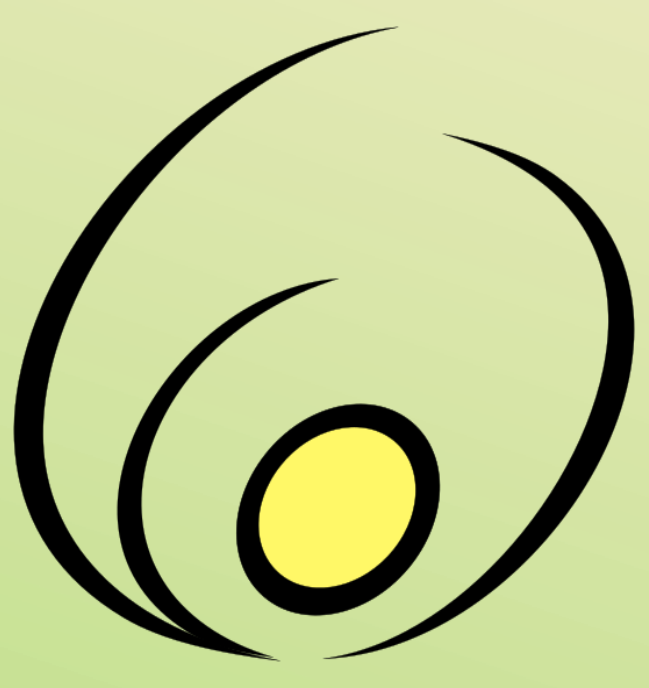

Fórum de

\section{Pró-Reitores}

\section{de Extensão}

\section{das Instituições}

\section{Públicas de}

\section{Educação Superior}

Brasileiras
Open access $\delta$ free available online

Revista Brasileira de Extensão Universitária

v. 8, n. 3, p. 185-192 set.- dez. 2017 e-ISSN 2358-0399

DOI: https://doi.org/10.24317/2358-0399.2017v8i3.6806

\title{
Feira de ciências agrárias de Monte Carmelo: relato de experiência de um projeto de extensão universitária com alunos do ensino médio
}

\author{
Eliza Vieira Davi ${ }^{1}$ \\ Lívia Mendonça de Aguiar ${ }^{2}$ \\ Carla Cristine Neves Mamede 3
}

Resumo: O Ensino Médio é uma fase em que os estudantes lidam com as expectativas sobre o futuro e ingresso ao Ensino Superior. Assim, atividades extensionistas sobre o tema são importantes para auxiliá-los na escolha profissional. O objetivo deste trabalho foi relatar a realização da Feira de Ciências Agrárias de Monte Carmelo e apresentar seu impacto diante dos estudantes participantes. A Feira foi um evento de extensão que trouxe os estudantes do Ensino Médio para a universidade e promoveu palestras com temas relacionados à Educação Superior e aos cursos de Agronomia e Engenharia Florestal, visitas aos laboratórios e atividades práticas. Ao final do evento, os participantes responderam um questionário sobre seu aprendizado e o quanto a Feira foi capaz de ajudá-los na escolha profissional. Os resultados mostraram que $43,5 \%$ dos estudantes participaram da Feira porque queriam adquirir conhecimentos sobre Ciências Agrárias, pois pretendiam seguir uma carreira desta área de conhecimento. Além disso, 58\% dos alunos disseram que nunca participaram de evento semelhante devido à falta de oferta desse tipo de atividade. Além disso, 93\% dos participantes consideraram que a Feira os ajudou na decisão da escolha profissional. Por fim, cerca de $70 \%$ deles se interessaram em fazer Agronomia, enquanto $17 \%$ afirmaram que fariam Engenharia Florestal. A realização de atividades extensionistas como esta proporciona uma aproximação entre a universidade e a comunidade escolar, permitindo que as instituições divulguem conhecimento acadêmico e busquem despertar nos jovens a vontade de ingressar no Ensino Superior.

Palavras-chave: Atividade Extensionista, Relação Instituição-Comunidade, Escolha Profissional

Content shared under Creative Commons Attribution 3.0 Licence CC-BY

1 Mestre em Ciências e técnica do Laboratório de Práticas Biológicas da Universidade Federal de Uberlândia - UFU. Rua Goiás, 2000, Monte Carmelo, MG, Brasil. CEP: 38500-000. evdavi@ufu.br (autora para correspondência)

2 Bióloga e técnica do Laboratório de Doenças Parasitárias da Universidade Federal de Uberlândia - UFU. Imaguiar@ufu.br 
Monte Carmelo Agrarian Sciences Fair: experience report on a university extension project with high school students

\begin{abstract}
High School is a period in which students deal with their expectations concerning the future, and the university entrance. Thus, extension activities on the subject are important for their career selection process. This paper aimed at reporting Monte Carmelo Agricultural Sciences Fair and its impact on the participants. The Fair was an extension event that brought high school students to the university and promoted lectures on themes related to Higher Education, Agronomy and Forest Engineering courses, laboratory tours and practical activities. At the end of the event, the participants answered a questionnaire on what they had learned, and how helpful the Fair was in their career selection process. According to the results, $43.5 \%$ of the students took part in the event in order to acquire knowledge on Agrarian Sciences, due to their future plans to pursue this career. In addition, $58 \%$ of the students claimed they had never participated in a similar event due to the lack of offer of this type of activity. Moreover, $93 \%$ of the participants claimed that the Fair was helpful in the career selection process. Finally, approximately $70 \%$ of them developed an interest in studying Agronomy, while $17 \%$ said they would study Forest Engineering. The fulfillment of such activities brings the University and the school community together, allowing the institutions to disseminate academic knowledge, and to attempt to arouse in the youngsters the desire to pursue Higher Education.
\end{abstract}

Keywords: Extension Activity, Institution-Community Relation, Career Selection

Feria de Ciencias Agrarias de Monte Carmelo: relato de experiencia de un proyecto de extensión universitaria con alumnos de la escuela secundaria

Resumen: La Escuela Secundaria es una fase en la que los estudiantes tratan con expectativas sobre el futuro y acceso a la Enseñanza Superior. Así actividades extensionistas sobre el tema son importantes para ayudarlos en la elección profesional. El objetivo de este trabajo fue detallar la realización de la Feria de Ciencias Agrarias de Monte Carmelo y presentar su impacto ante los estudiantes. La Feria fue un evento de extensión que trajo los estudiantes de la Escuela Secundaria hacia la universidad y promovió conferencias con temas relacionados a los cursos de Agronomía e Ingeniería Forestal, visitas a los laboratorios y actividades prácticas. Al final del evento, los participantes respondieron un cuestionario sobre su aprendizaje y a respecto de cómo la Feria fue capaz de ayudarlos a elegir su profesión. Los resultados mostraron que $43,5 \%$ de los estudiantes participaron de la Feria porque querían adquirir conocimientos sobre Ciencias Agrarias. Además, $58 \%$ de los alumnos dijeron que nunca habían participado en evento similar debido a la falta de oferta de ese tipo de actividad. Otro dato mostró que $93 \%$ consideraron que la Feria los ayudó a tomar uma decisión al elegir su profesión. Por último, aproximadamente $70 \%$ de ellos se interesaron por la carrera de Agronomía, mientras que $17 \%$ afirmaron que estudiarían Ingeniería Forestal. La realización de actividades como esta proporciona una aproximación entre la Universidad y la comunidad escolar, permitiendo que las instituciones divulguen conocimiento académico y busquen despertar en los jóvenes el deseo de entrar en la Universidad.

Palabras-clave: Actividades Extensionistas, Relación Institución-Comunidad, Elección Profesional

\section{Introdução}

O Ensino Médio no Brasil, que é a última etapa da Educação Básica, representa um desafio aos estudantes, pois é nesta fase que os alunos lidam com suas particularidades e expectativas sobre o futuro e ingresso ao Ensino Superior. Assim, estes necessitam reconhecer suas potencialidades e, consequentemente, escolher uma carreira profissional. A opção por uma determinada profissão nem sempre é um processo simples para o estudante, e pode gerar estados de angústia e estresse. Durante esse processo de escolha, o aluno deve observar fatores como renda, perspectiva de empregabilidade, oportunidades econômicas e, principalmente, vocação e aptidão acadêmica (BARTALOTTI; MENEZES-FILHO, 2007, GIOVINAZZO-JÚNIOR, 2016).

Para muitos estudantes, especialmente aqueles jovens provenientes de classes econômicas desfavorecidas e de escolas públicas, a escolha da profissão caracteriza-se pela busca de equilíbrio entre o objetivo almejado e o que é possível de ser realizado (SOBROSA et al., 2014). Além disso, muitos alunos têm dificuldade em acessar informação de qualidade sobre o Ensino Superior, somado ao fato de que esses estudantes não se sentem preparados ou capazes de ingressar na Universidade, especialmente a pública, que muitas vezes é vista como elitizada (NASCIMENTO et al., 2015). 
Isso reforça a importância de ações extensionistas que forneçam informações à comunidade escolar sobre as formas de ingresso à universidade, e quais cursos superiores eles têm a oportunidade de estudar, principalmente na universidade pública presente no seu entorno. A extensão universitária tem o intuito de viabilizar a relação transformadora entre a universidade e a sociedade. Assim, a extensão universitária, dentre seus vários aspectos, se mostra como um trabalho interdisciplinar capaz de atender às demandas da sociedade ao mesmo tempo em que amplia e propaga os saberes gerados na universidade (BENETTI et al., 2015). Essa interdisciplinaridade pode ser promovida junto à comunidade por meio de feiras que atuam de forma a promover uma atitude reflexiva, problematizadora e investigativa (WANDERLEY, 1999).

A Universidade Federal de Uberlândia (UFU), em Monte Carmelo, oferece entre outros, os cursos de Agronomia e Engenharia Florestal, que cada vez mais têm sido procurados pelos alunos, mas que ainda não são totalmente conhecidos e almejados pelos estudantes. Estes cursos compõem a grande área de Ciências Agrárias, que constituem um conjunto de conhecimentos que está diretamente relacionado com o binômio homemnatureza (ALCANTARA et al., 2014). O profissional formado em Agronomia pode desempenhar seu trabalho em vários setores, seja na produção de alimentos, na proteção ao meio ambiente, na agricultura alternativa e no desenvolvimento da ciência e da pesquisa agropecuária (BRANDENBURG, 2002, ABREU et al., 2012). O trabalho do engenheiro florestal, por sua vez, pode ser desempenhado em várias áreas, sendo relevante na integração entre a conservação do meio ambiente e o desenvolvimento econômico por meio do manejo sustentável das florestas (SANTOS, 2006, ARRIVABENI, 2014).

Frente a esse cenário, foi realizado o projeto de extensão intitulado Feira de Ciências Agrárias de Monte Carmelo, com o intuito de promover um evento para apresentar aos alunos do Ensino Médio as diversas áreas de atuação do agrônomo e do engenheiro florestal, por meio de palestras, visitas aos laboratórios e atividades práticas, de maneira interdisciplinar, contextualizada e integrada.

A ação de trazer os alunos do Ensino Médio para a universidade é uma forma de motivá-los a ingressar no Ensino Superior e auxiliar sua escolha profissional. Assim, o objetivo do presente trabalho foi relatar a realização da Feira de Ciências Agrárias de Monte Carmelo e apresentar sua avaliação e impacto diante dos estudantes participantes, fortalecendo a parceria entre a comunidade escolar e a universidade.

\section{Metodologia}

A Feira ocorreu no formato de um evento científico no próprio campus da Universidade. As atividades, organizadas de forma integrada e interdisciplinar, foram executadas por discentes, docentes e técnicos dos cursos de Agronomia e Engenharia Florestal. A primeira palestra abordou "A Universidade Federal de Uberlândia em Monte Carmelo" mostrando a estrutura da universidade e o plano diretor das futuras instalações, quais cursos são atualmente oferecidos, dentre outras informações sobre o campus. A segunda palestra retratou "O mercado de trabalho na Agronomia" e a terceira abordou a "Engenharia florestal: universidade e mercado de trabalho". Ambas as palestras mostraram aos alunos o mercado de trabalho, as áreas de pesquisa e discutiram a prática do profissional.

Após as palestras, os alunos foram direcionados aos laboratórios de ensino da Universidade para visitarem e realizarem algumas atividades práticas. Um dos laboratórios que os estudantes puderam conhecer foi o de Práticas Biológicas, no qual foram apresentadas várias peças anatômicas utilizadas na disciplina de anatomia e fisiologia animal. Os alunos puderam conhecer como são o coração, os pulmões e os rins de bovinos e suínos, bem como aprender como funciona o sistema digestório de ruminantes. Outro laboratório visitado pelos estudantes foi o de Manejo e Conservação do Solo e da Água. Neste laboratório, foi apresentada uma aula prática sobre a importância de se manter a cobertura vegetal do solo na prevenção de casos de erosão. Além disso, os alunos tiveram a oportunidade de conhecer e tocar em três diferentes tipos de solo com composição arenosa, siltosa e argilosa. O Laboratório de Entomologia também foi visitado pelos alunos que puderam ter contato com as pesquisas do setor e conhecer o rico insetário que compõe o laboratório. Alguns insetos presentes no insetário são considerados pragas em diversas culturas, tendo grande importância nas Ciências Agrárias. O último laboratório visitado pelos alunos foi o de Botânica, onde os estudantes puderam aprender a manipular um microscópio de luz visível e realizar as atividades práticas de visualização de estômatos em folhas, e grãos de pólen da flor de hibisco.

Ao final das atividades da Feira de Ciências Agrárias de Monte Carmelo, os participantes receberam uma ficha avaliativa, contendo perguntas sobre a organização, a programação científica e a estrutura da Feira, bem como sobre o desempenho da equipe envolvida no trabalho. A ficha abordou também uma autoavaliação desses estudantes quanto ao seu aprendizado e quanto à contribuição da Feira na escolha profissional. O questionário continha 31 questões objetivas e três perguntas discursivas nas quais os estudantes poderiam manifestar livremente sua opinião sobre o evento, avaliando aspectos que considerassem negativos e positivos, bem como propor sugestões (ANEXO 1 material suplementar).

Dos 37 alunos do Ensino Médio participantes, 31 entregaram a ficha devidamente respondida. As informações foram organizadas em um banco cujos dados foram transformados em porcentagem para análise dos resultados obtidos.

\section{Resultados e Discussão}

\section{Perfil dos alunos participantes}

A Feira de Ciências Agrárias de Monte Carmelo contou com 58 inscrições de estudantes de 4 escolas de Monte 
Carmelo: 16 de instituições particulares e 42 de escolas públicas (Tabela 1). Assim, 74,1\% dos estudantes inscritos eram provenientes de escolas públicas, o que reforça o papel extensionistas da Universidade em promover o relacionamento com a comunidade do seu entorno, especialmente com os alunos em condição socioeconômica menos favorecida.

Participaram da Feira 37 inscritos: mais de $89 \%$ destes eram estudantes do $2^{\circ}$ ano do Ensino Médio, 1 aluno $(2,7 \%)$ cursava o $1^{\circ}$ ano e os demais $(8,1 \%)$ eram estudantes do $3^{\circ}$ ano. A idade dos participantes variou de 15 a 18 anos, sendo que $45,9 \%$ tinham 17 anos e a maioria dos participantes era do gênero feminino $(70,3 \%)$ (Tabela 2$)$.

\section{Avaliação das atividades práticas}

Com relação às visitas e atividades práticas que os estudantes realizaram nos laboratórios, a análise dos dados mostrou que a maioria dos alunos gostou do ambiente laboratorial e se identificou com as atividades desenvolvidas. Quando questionados se tinham se identificado com o Laboratório de Práticas Biológicas, $15 \%$ dos estudantes responderam que tinham gostado mais ou menos, $30 \%$ bastante e $55 \%$ tinham gostado muito. Com relação ao Laboratório de Manejo e Conservação do Solo e da Água, 5\% dos estudantes responderam não ter gostado de nada, $11 \%$ afirmaram que pouco se identificaram, $28 \%$ mais ou menos, $28 \%$ bastante e $28 \%$ se identificaram muito. Sobre o Laboratório de Entomologia, 5\% dos alunos participantes se identificaram pouco, $30 \%$ mais ou menos, $30 \%$ bastante e $35 \%$ se identificaram muito. Por fim, quando questionados se haviam se identificado com o Laboratório de Botânica, $8 \%$ responderam que mais ou menos, $19 \%$ bastante e $73 \%$ afirmaram que gostaram muito (Figura 1).

\section{Avaliação da ação extensionista}

Os alunos participantes responderam também sobre o quanto tinha sido importante para eles participar da Feira de Ciências Agrárias de Monte Carmelo e todos eles disseram que foi importante ou muito importante terem estado presentes. Os estudantes, quando questionados sobre o principal motivo pelo qual participaram da Feira (Tabela 3), disseram que compareceram ao evento porque queriam adquirir conhecimentos na área agrícola, uma vez que pretendem fazer algum curso superior nesta área. O segundo motivo mais relatado pelos estudantes foi que eles participaram do evento para conhecer como eram os cursos de Agronomia e Engenharia florestal. Alguns estudantes responderam também que tinham curiosidade em ver como seria realizada a Feira, bem como ver como eram as instalações da UFU em Monte Carmelo. Apenas um aluno respondeu que queria, através de sua presença na Feira, mostrar ser um aluno participativo. Os alunos compareceram à Feira de maneira espontânea, portanto entender os motivos que os atraíram até a universidade é importante para se compreender as expectativas dos estudantes sobre um evento como esse.

Tabela 1. Comparação entre os estudantes do Ensino Médio que se inscreveram e os que participaram da Feira de Ciências Agrárias de Monte Carmelo.

$\begin{array}{cccc}\mathbf{N}^{\mathbf{0}} \text { de } & \% \text { de } & \mathbf{N}^{0} \text { de } & \% \text { de } \\ \text { inscritos } & \text { inscritos } & \text { participantes } & \text { participantes }\end{array}$

Escolas públicas

\begin{tabular}{|lcccc}
\hline Escola Estadual Padre Vicente Lopes Perez & 34 & $58,6 \%$ & 21 & $56,8 \%$ \\
\hline Escola Estadual Gregoriano Canedo & 8 & $13,8 \%$ & 5 & $13,5 \%$ \\
\hline Total parcial & $\mathbf{4 3}$ & $\mathbf{7 4 , 1 \%}$ & $\mathbf{2 6}$ & $\mathbf{7 0 , 3 \%}$ \\
\hline Escolas particulares & & & 11 & $29,7 \%$ \\
\hline Colégio Alpha COC & 13 & $22,4 \%$ & 0 & $0,0 \%$ \\
\hline Colégio Nossa Senhora do Amparo & 3 & $5,2 \%$ & $\mathbf{1 1}$ & $\mathbf{2 9 , 7} \%$ \\
\hline Total parcial & $\mathbf{1 6}$ & $\mathbf{2 7 , 6 \%}$ & $\mathbf{3 7}$ & $\mathbf{1 0 0 , 0 \%}$ \\
\hline Total & $\mathbf{5 8}$ & $\mathbf{1 0 0 , 0 \%}$ & & \\
\hline
\end{tabular}

Fonte: dos autores. 
Tabela 2. Informações sobre a escolaridade, idade e gênero dos estudantes que participaram da Feira de Ciências Agrárias de Monte Carmelo.

\begin{tabular}{|c|c|c|c|c|c|}
\hline & & Escolas públicas & Escolas particulares & Total & $(\%)$ \\
\hline \multirow{3}{*}{ Ensino Médio } & $1^{\mathrm{o}}$ ano & 0 & 1 & 1 & $2,7 \%$ \\
\hline & $2^{\circ}$ ano & 23 & 10 & 33 & $89,2 \%$ \\
\hline & $3^{\circ}$ ano & 3 & 0 & 3 & $8,1 \%$ \\
\hline \multirow[t]{2}{*}{ Total } & & 26 & 11 & 37 & $100,0 \%$ \\
\hline & 15 anos & 0 & 1 & 1 & $2,7 \%$ \\
\hline \multirow[t]{3}{*}{ Idade } & 16 anos & 13 & 3 & 16 & $43,3 \%$ \\
\hline & 17 anos & 10 & 7 & 17 & $45,9 \%$ \\
\hline & 18 anos & 3 & 0 & 3 & $8,1 \%$ \\
\hline Total & & 26 & 11 & 37 & $100,0 \%$ \\
\hline \multirow[t]{2}{*}{ Gênero } & $\mathrm{M}$ & 7 & 4 & 11 & $29,7 \%$ \\
\hline & $\mathrm{F}$ & 19 & 7 & 26 & $70,3 \%$ \\
\hline Total & & 26 & 11 & 37 & $100,0 \%$ \\
\hline
\end{tabular}

Fonte: dos autores.

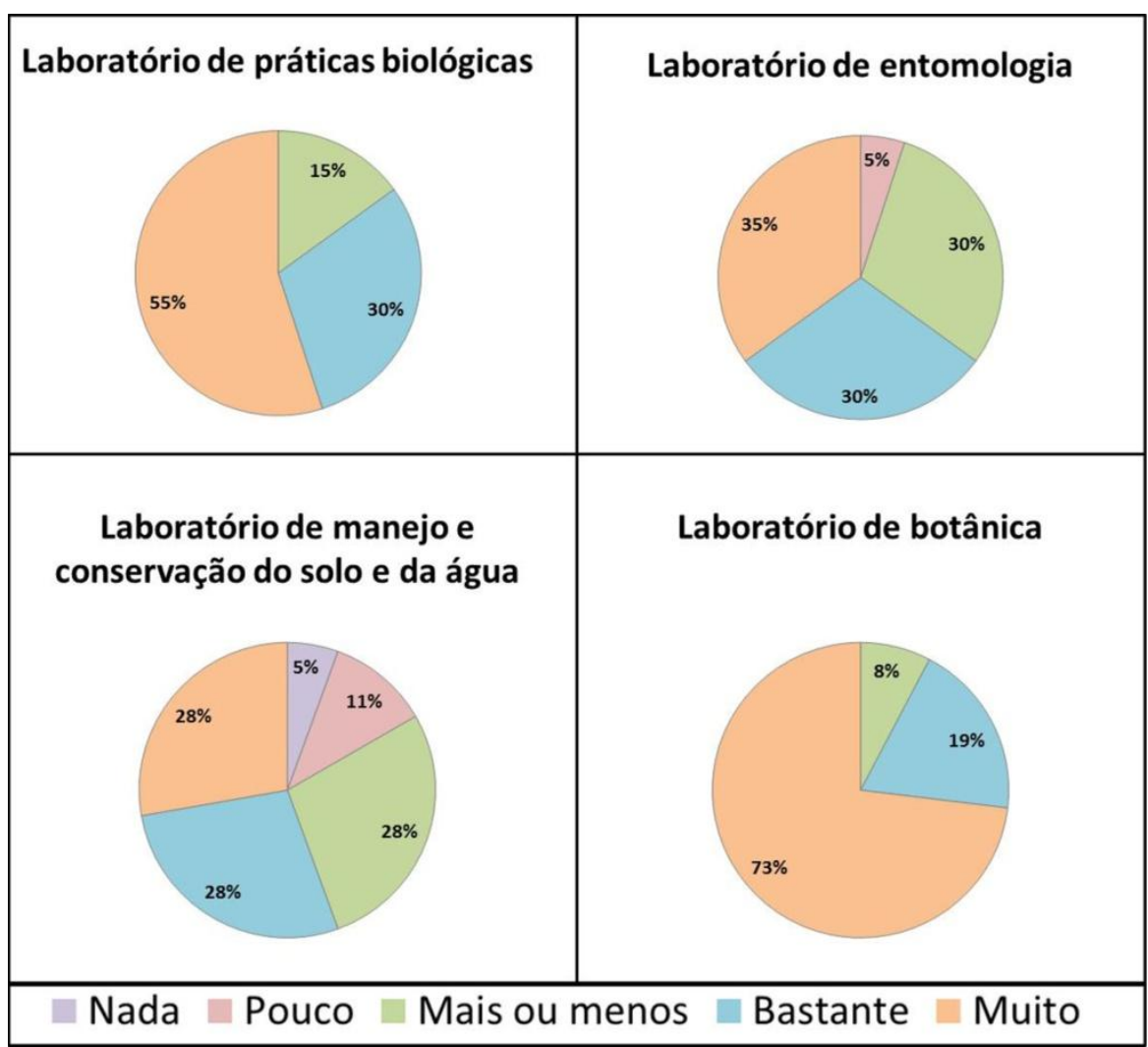

Figura 1. Respostas dos alunos participantes sobre o quanto se identificaram com os diferentes laboratórios da UFU durante a Feira de Ciências Agrárias de Monte Carmelo. Fonte: dos autores. 
Aproximadamente $73 \%$ dos alunos disseram que nunca haviam participado de algum evento semelhante à Feira de Ciências Agrárias de Monte Carmelo e a maioria deles respondeu que o motivo era a falta de oferta desses eventos na cidade (Figura 2). Outros alunos responderam que nunca haviam participado porque os professores ou a escola não os incentivavam a participar, ou disseram ter falta de tempo, ou porque desconheciam a importância de eventos como a Feira para ajudá-los a conhecer melhor como é uma universidade. Com esses resultados, é notável a carência dos eventos de extensão na cidade de Monte Carmelo, principalmente aqueles que envolvem a participação dos alunos do Ensino Médio. Incluir esses alunos nas atividades desempenhadas pela universidade é muito importante para a tomada de decisão quanto à escolha da sua carreira profissional.
Segundo o Instituto de Ciências Agrárias (ICIAG, s. d.), o curso de Agronomia de Monte Carmelo foi aprovado pelo Conselho Universitário da UFU em 2010 e o curso de Engenharia Florestal, por sua vez, foi aprovado em 2013. Como a universidade está há pouco tempo na cidade e, especialmente o curso de Engenharia Florestal foi recentemente aberto, os estudantes do Ensino Médio tinham curiosidade em conhecer o campus e ver como funcionava a universidade. Durante uma conversa com esses alunos em uma das palestras realizadas, alguns estudantes perguntaram quais os valores das mensalidades, por desconhecimento de que a UFU é uma Universidade Federal e, portanto, gratuita. Eventos como a Feira demostram a importância de aproximar esses alunos do Ensino Médio à Universidade, pois muitas vezes a comunidade escolar desconhece tanto as formas de ingresso ao Ensino Superior, quanto a gratuidade dos cursos na instituição.

Tabela 3. Principais motivos pelos quais os estudantes participaram da Feira de Ciências Agrárias de Monte Carmelo.

\begin{tabular}{lcc}
\hline \multicolumn{1}{c}{ Opção de resposta } & Quantidade de respostas & $\%$ \\
\hline Adquirir conhecimentos na área. & 27 & $43,5 \%$ \\
\hline Encontrar colegas e amigos. & 0 & $0,0 \%$ \\
\hline Conhecer sobre os cursos de agronomia e engenharia florestal da UFU. & 24 & $38,7 \%$ \\
\hline Conhecer as instalações da UFU. & 5 & $8,1 \%$ \\
\hline Ganhar horas de atividades extracurriculares. & 0 & $0,0 \%$ \\
\hline Poder demonstrar ser um aluno participativo. & 1 & $1,6 \%$ \\
\hline Não precisar estar em sala de aula durante a realização do evento. & 0 & $0,0 \%$ \\
\hline Algum professor mencionou que participar dessa atividade valerá algum ponto. & 0 & $0,0 \%$ \\
\hline Será necessário fazer algum relatório sobre a Feira. & 0 & $0,0 \%$ \\
\hline Curiosidade sobre como seria a Feira. & 5 & $8,1 \%$ \\
\hline Ganhar brindes e lanche. & 0 & $0,0 \%$ \\
\hline
\end{tabular}

Fonte: dos autores.

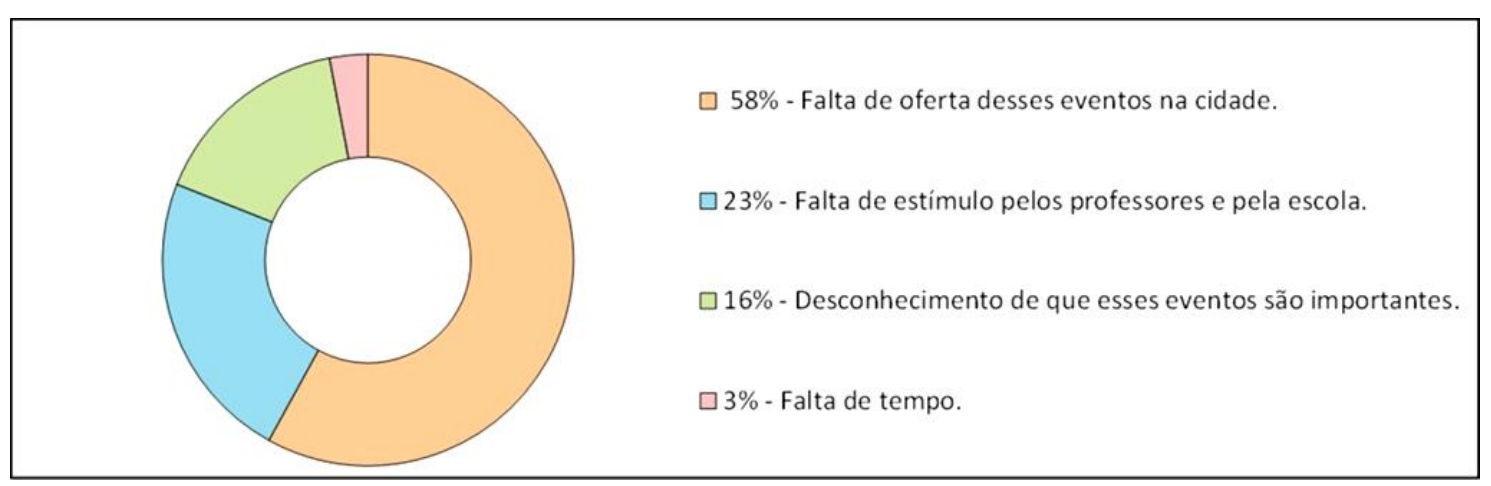

Figura 2. Respostas dos alunos participantes quando questionados sobre o porquê nunca tinham participado de um evento de extensão. Fonte: dos autores. 
Por fim, 93\% dos estudantes responderam que a Feira de Ciências Agrárias de Monte Carmelo os ajudou na tomada de decisão da escolha profissional. Quando indagados se eles gostariam de fazer o curso de Agronomia, aproximadamente $71 \%$ dos alunos disseram que sim, $18 \%$ responderam que talvez e $11 \%$ afirmaram que não (Figura 3). O curso de Agronomia é o mais concorrido atualmente na UFU em Monte Carmelo e, além da carreira do engenheiro agrônomo ser mais conhecida, o curso na região também já está estabelecido há mais tempo. Assim, os estudantes que já gostavam dessa área de conhecimento acabaram por confirmar sua predileção e optar pela escolha de fazer o curso de Agronomia. Por outro lado, quando questionados se gostariam de fazer o curso de Engenharia Florestal, aproximadamente $52 \%$ responderam que talvez, $31 \%$ disseram que não e apenas $17 \%$ afirmaram que sim. Como uma grande parcela dos alunos disse que não gostaria de fazer o curso, isso demonstra que eles responderam o questionário com sinceridade e que a Feira foi importante para ajudá-los a escolher a carreira profissional que querem seguir. Ao mesmo tempo, esse dado nos chama a atenção para uma maior divulgação sobre a carreira do engenheiro florestal e a importância desse profissional para a região. Talvez assim, a universidade tenha mais alunos interessados em seguir essa carreira.

Portanto, o presente trabalho relatou como a Feira de Ciências Agrárias de Monte Carmelo foi capaz de promover o estreitamento entre o Ensino Médio e o Ensino Superior uma vez que o evento proporcionou a troca de saberes entre a Universidade e a comunidade escolar. A Feira tornou acessível à todos os alunos participantes, especialmente àqueles de escolas públicas, a oportunidade de conhecer a UFU, suas instalações e seus cursos de Agronomia e Engenharia Florestal, ajudando-os na tomada de decisão para a escolha de uma carreira profissional.

\section{Considerações finais}

Este trabalho pôde enfatizar o quanto as escolas, especialmente as públicas, são carentes de atividades que aproximem seus alunos da Universidade, uma vez que os alunos se mostraram muito interessados nas visitas e atividades práticas. Além disso, esses estudantes afirmaram que a Feira foi muito importante para eles e que nunca tinham participado de um evento semelhante, devido à falta de oportunidades como esta em Monte Carmelo. Este trabalho mostrou ainda que os participantes da Feira queriam adquirir conhecimentos na área agrícola, uma vez que pretendiam ingressar em algum curso superior nesta área. Isso mostra que eles têm interesse em conhecer mais a respeito e o evento foi capaz de ajudá-los a tomar a decisão sobre qual curso ingressar, visto que a maioria deles afirmou que faria o curso de Agronomia e que talvez fizesse o curso de Engenharia Florestal.

A realização de projetos de extensão como a Feira de Ciências Agrárias de Monte Carmelo, envolvendo a participação de estudantes do Ensino Médio, representa um importante elo entre a UFU e a comunidade escolar do seu entorno. É através de ações como estas que a Universidade divulga conhecimento acadêmico e busca despertar nos jovens a vontade de ingressar no Ensino Superior, proporcionando a eles oportunidades de reflexão e de tomada de decisão.

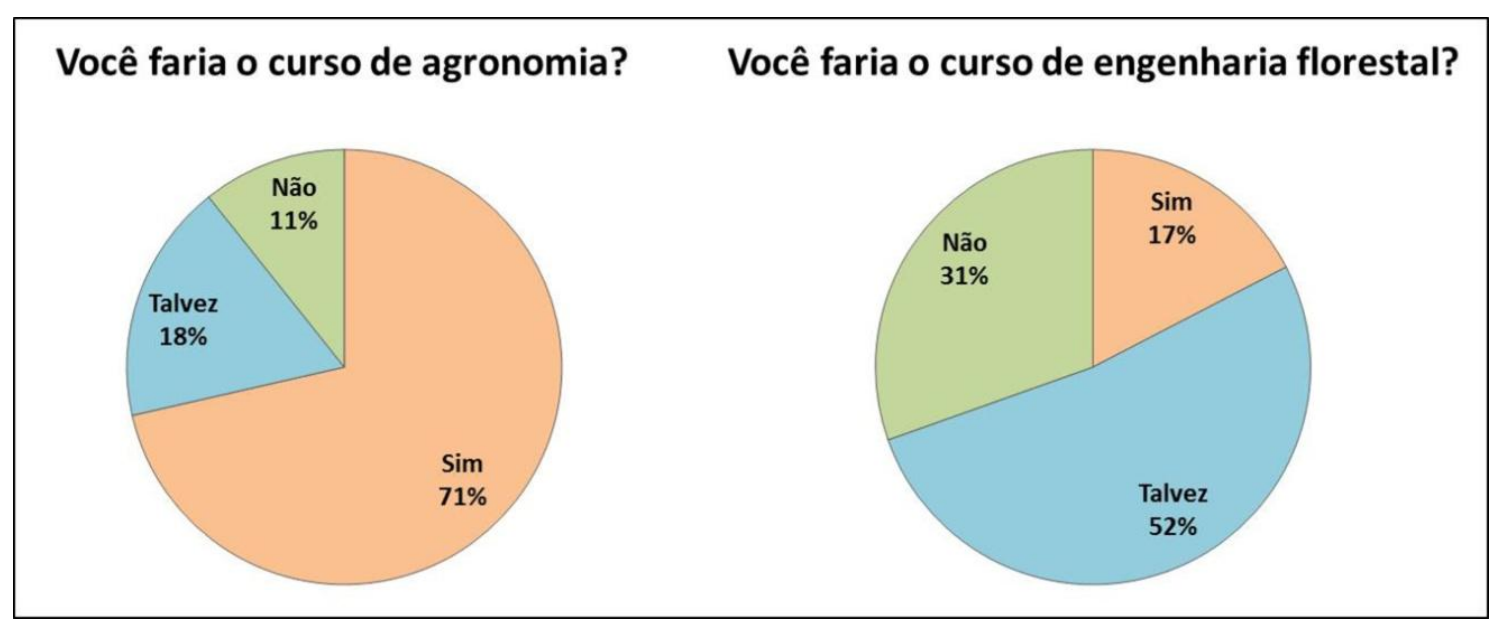

Figura 3. Respostas dos alunos participantes quando questionados se fariam os cursos de Agronomia e Engenharia Florestal após a participação na Feira de Ciências Agrárias de Monte Carmelo. Fonte: autoria própria. 


\section{Agradecimentos}

Aos alunos que participaram da Feira de Ciências Agrárias de Monte Carmelo e tão gentilmente responderam ao questionário. Aos diretores do Colégio Nossa Senhora do Amparo, da Escola Estadual Gregoriano Canedo, do Colégio Alpha COC e da Escola Estadual Padre Vicente Lopes Perez. Aos discentes que participaram do planejamento e execução da Feira, em especial Fernanda R. Veloso, Luis Fernando V. Silva, Isadora S. Roque e Igor B. L. Moreira. Aos técnicos e professores que ministraram as palestras e auxiliaram nas atividades, especialmente Prof. Dr. Eusímio F. F. Júnior, Me. Fábio J. Carvalho e Prof. $^{\text {a }}$ Dr. $^{\text {a }}$ Ana Carolina S. Siquieroli. Ao Instituto de Ciências Agrárias e à PróReitora de Pesquisa e Extensão da Universidade Federal de Uberlândia, pelo incentivo e apoio à realização desse projeto.

\section{Contribuição de cada autor}

E. V. D. atuou no planejamento e execução das atividades do projeto, organização dos dados e redação do texto e resumos, além da edição e revisão do artigo. L. M. A. realizou o planejamento do projeto e edição e revisão crítica do texto. C. C. N. M. atuou no planejamento e execução das atividades do projeto, bem como na edição e revisão crítica do artigo.

\section{Referências}

ABREU, L. S.; BELLON, S.; BRANDENBURG, A.; OLLIVIER, G.; LAMINE, C.; DAROLT, M. R.; AVENTURIER, P. Relações entre agricultura orgânica e agroecologia: desafios atuais em torno dos princípios da agroecologia. Desenvolvimento e Meio Ambiente, v. 26, p. 143-160, 2012.

ALCANTARA, F. D. et al. Bacharelado em agronomia: o ensino nas universidades para o exercício profissional. In: CONGRESO IBEROAMERICANO DE CIENCIA, TECNOLOGÍA, INNOVACIÓN Y EDUCACIÓN, 2014, Buenos Aires. Anais... Buenos Aires, 2014. p 111.

ARRIVABENI, B. S. Ensino de engenharia florestal no Brasil e na Espanha. 2014. Monografia (Graduação em engenharia florestal) - Universidade Federal de Viçosa, Viçosa, 2014.

BARTALOTTI, O.; MENEZES-FILHO, N. A relação entre o desempenho da carreira no mercado de trabalho e a escolha profissional dos jovens. Economia Aplicada, v. 11, n. 4, p. 487-505, 2007.

BENETTI, P. C.; SOUSA, A. I.; DO NASCIMENTO SOUZA, M. H. Creditação da extensão universitária nos cursos de graduação: relato de experiência. Revista
Brasileira de Extensão Universitária, v. 6, n. 1, p. 25 32, 2015.

BRANDENBURG, A. Movimento agroecológico: trajetória, contradições e perspectivas. Desenvolvimento e Meio Ambiente, n. 6, p. 11-28, 2002.

GIOVINAZZO- JÚNIOR, C. A. Os jovens, o Ensino Médio e a vida que os estudantes não encontram na escola. InterMeio: Revista do Programa de PósGraduação em Educação, v. 22, n. 44, p. 49-87, 2016.

ICIAG - INSTITUTO DE CIÊNCIAS AGRÁRIAS. Graduação em Agronomia - Campus Monte Carmelo. Uberlândia, Universidade Federal de Uberlândia, s. d. Disponível em: < http://www.iciag.ufu.br/node/415 > Acessado em out. 2016.

NASCIMENTO, T. G. V. et al. Análise do nível de conhecimento e motivação de alunos do ensino médio rumo ao ensino superior: Projeto Diálogos sobre o que Significa Cursar Engenharia. Revista Brasileira de Extensão Universitária, v.6, n.1, p. 7-13, 2015.

SANTOS, A. F. Caracterização do ensino da Engenharia Florestal no Brasil. Revista Educação Agrícola Superior, v. 21, n. 1, 2006.

SOBROSA, G. M. R.; SANTOS, A. S. D.; OLIVEIRA, C. T. D.; DIAS, A. C. G. Perspectivas de Futuro Profissional para Jovens Provenientes de Classes Socioeconômicas Desfavorecidas. Temas em Psicologia, v. 22, n. 1, p. 223-234, 2014.

WANDERLEY, E. C. Feiras de ciências enquanto espaço pedagógico para aprendizagens múltiplas. Dissertação (Mestrado) - CEFET-MG, Belo Horizonte, 1999.

\section{$* * *$}

Como citar este artigo:

DAVI, E. V.; AGUIAR, L. M. DE; MAMEDE, C. C. N. Feira de ciências agrárias de Monte Carmelo: relato de experiência de um projeto de extensão universitária com alunos do ensino médio. Revista Brasileira de Extensão Universitária, v. 8, n. 3, p. 185-192, 2017. Disponível em: < https://periodicos. uffs.edu.br/index.php/RBEU/article/view/6806/pdf > 